\title{
Customer Relationship Malevolence: A Reflection on Ac- counting, Marketing and Customer Valuation
}

\author{
Kenneth Weir \\ Centre for Philosophy and Political Economy, University of Leicester, Leicester, UK, \\ khw11@le.ac.uk
}

\begin{abstract}
Ideas centring on knowing and understanding the customer have been core concerns of business since the 1960s. As a result, several attempts to understand the customer have been devised, leading to the generation of data collection systems and calculative technologies that try to provide numerical understanding of the customer, which now lies at the heart of contemporary customer management schemes. However, these technologies can produce several social consequences. This paper discusses valuation metrics used in customer management systems and outlines the negative issues that can result from widespread usage.
\end{abstract}

Keywords: Customer Valuation, Customer Management, Commodification, Marginalisation

\section{Introduction}

The "customer" archetype has been central to business and marketing since, at least, the 1950 s and 1960s, when academics recognised the importance of the customer (for example, Levitt 1962), suggesting that sustained focus on meeting customer needs could yield significant gains for firms, and urging managers to pursue a regal-like treatment of the customer (cf. Drucker 1954). Such initial attempts to bring customers to the core of business oriented the essential productive functions and activities of a business towards meeting customer needs, on the basis that customers drive profits:

It is the customer who determines what a business is [...] through being willing to pay for a good or service [...] What the business thinks it produces is not of first importanceespecially not to the future of the business and its success. What the customer thinks he is buying, what he considers "value" is decisive-it determines what a business is, what it produces and whether it will prosper" (Drucker 1954, 35).

This pairing of customers and value spawned intensification into the study of marketing (Boyce 2000; Yani-de-Soriano and Slater 2009), notably on anticipating the needs of customers through examining levels of customer satisfaction, but also spawning business focus into areas of customer intimacy (Boyce 2000; Cuganesen 2008), and how practices may be developed to enact the broader focus on intimacy stressed by the normative managerial literature prevalent at the time, but also to create intimate knowledge about the customer's relationship with the organisation (for an overview see Cuganesen 2008).

However, interest in the customer resurfaced in a more intense form in the 1980s alongside the growing consumer culture (Webster 1988; Boyce 2000; Yani-de-Soriano and Slater 2009) and contemporary analyses of the customer built upon the key concepts of the customer relationship outlined in the 1960s, as the marketing function in organisations attempted to integrate customer needs with strategic planning (Webster 1988), and thus re-orienting the customer as a key platform for developing strategy and delivering firm value. This also led to renewed awareness on understanding customer value by both accounting and marketing academics (Boyce 2000; Weir 2008). Concomitantly, management academics were drawn to analyses of the contemporary business environment, leading to numerous studies on under- 
standing and developing strategies that would enhance (global) competitiveness (see, for example, Porter 1985). The marrying of disciplinary focus further entrenched the customer at the heart of strategic concerns, allowing academics and practitioners to advance tools for gathering and analysing information about a company's customers and competitors (Simmonds 1982; Bromwich 1990, Guilding and McManus 2002), therefore utilising existing accounting information for inter-functional purposes that supported the overall competitive strategy of the organisation (Roslender 1995). Customers, in short, became quantifiable (cf. Vaivio 1997) and a chief source of competitive advantage in the global competitive environment.

\section{Valuing the Customer}

Initial explorations into the link between customers and value then followed such assertions in the 1950s and 60s and was facilitated by tools such as surveys that captured a range of non-financial data serving as some of the key indicators of customer satisfaction (Boyce 2000), whilst financial indicators such as price and revenue were also utilised (Ibid.). However, with the growth in the data-processing capability of computing and data storage in the 1980 s, efforts to understand customer needs and to measure customer value became more expansive. Subsequent attempts at valuation have followed three main waves. Firstly, customer accounting was introduced as a means of measuring proportionate profits attributable to specific customer groups, which was secondly extended through customer lifetime valuation which sought to estimate the relative value of a customer relationship over its expected life, and finally the shift towards value led to the establishment of customer equity calculations.

Customer profitability analysis (CPA) represents the first long-term undertaking of measuring customer value, and encapsulates several different techniques of investigation (Weir 2008). The calculations operate on the notion that some customers contribute more to the overall revenues, therefore profits, of an organisation than other customers, and the task of calculation is to provide managers with an understanding of the net effect of the differences between a range of customers. The calculation gauges the profits directly attributable to either individual customers, or to specific customer groups, by subtracting customer-specific costs (such as the costs of fulfilling the particular transaction) from the sales revenue for the customer under investigation (Bellis-Jones 1989; Foster and Gupta 1994).

Customer lifetime value (CLV) extends this by forecasting revenues and costs into future periods and has been attracting more attention from academics in recent years (Weir 2008); as such, there are numerous models proffered in the extant literature, with key variations on how the lifetime component of value can be reliably measured. On a basic level, the metric emphasises aspects of the customer relationship and builds these into the modelling process. For example, a key assumption in CLV literature is the perception that customers can regularly engage in cross-buying; that is, customers have different purchasing cycles and will buy goods or services from competitors, but may still conduct most of their transactions with one specific organisation. During these transactions, a company may temporarily lose sales revenue that would otherwise be associated with the customer, and to ensure loyalty, the company may offer reduced products to entice the customer "back" to the company. As a result, CLV models can incorporate these costs (the loss of revenue during switching, and costs of providing discounts) as well as model and emulate this switching behaviour in order to establish more reliable estimates of customer and competitor behaviour within a certain time frame (Berger et al. 2002).

This shift from profit to value, has also ingrained in organisations the impression of customers as assets (Rust et al. 2004), which have the capacity to create future economic benefit, and are thus a resource owned and controlled by the organisation for the purposes of creating value. To be sure this link between customers and creating value for the firm has been codified in normative managerial literature since the 1950s (Drucker 1954), and has been intensified in the intervening period by scholars (Miles and Snow 1987; Porter 1985) who have suggested generic strategies that exploit the link between customers and value. A 
third area of valuation techniques has explicitly included the link, or capacity, to create value within calculative frameworks.

Customer Equity (CE) is commonly described as the sum of individual discounted lifetime values of both present and future customers for the duration of the time they continue to transact with the company (Weir 2008). Approaches to measuring CE were formalised along concerns to fine the optimal balance between the acquisition of customers and customer retention (Blattberg and Deighton 1996), with the optimal level occurring when CE was at its highest. Crucial to its inception has been the theoretical advances in consumer behaviour as studies (for example Bayon et al 2002) have elaborated the possible conditions through which to better model patterns of cross-buying and the subsequent duration of customer retention. The CE model, however, can chart these for a range of different segments, allowing managers and markets to examine, in more detail than CLV models, the exact impact of any given customer segment or group upon overall firm value-this is achieved by finding the collective CLV of each segment and measuring it against any resulting increases in firm value levels in order to ascertain if particular marketing strategies have resulted in a favourable increase in firm value. The shifts -both favourable and unfavourable-can then be examined through additional data analysis of the customer relationship.

Underpinning both CLV and CE is customer relationship management (CRM) which is the subsequent management of customer relationships, wherein marketers and managers are concerned with the provision of individual and highly customised marketing services to specific customer segments based upon their apparent lifetime value, thus recognising elements of heterogeneity within a particular firm's customer or client base (see Verhoef 2003) and allocation of attention and marketing services is approximately proportionate to determined levels of customer value (Rust et al. 2000; Kumar et al. 2006), and even loyalty (Boyce 2000). Theoretically, this represents an attempt to optimise the efficient allocation of firm resources as, in the presence of limited (marketing) resources, priority is given to higher value customers on the basis that this may generate higher levels of revenue and firm value relative to the costs of providing alternative tailored marketing and services to lower value customers.

Inherent in this rhetoric is the notion that is possible to provide more to existing customers, and the knowledge created by the accounting and valuation models is central to the creation of related management schemes, and becomes a crucial component in knowing the customer (Vaivio 1999; Weir 2008; Cuganesen 2008; Haenlein and Kaplan 2009).

\section{Knowing the Customer}

Attendant with the growth of e-commerce and shifts in the contemporary business environment, knowledge assets and information-based organisations have emerged as a key focus for developing customer value concepts (see, Yani-de-Soriano and Slater 2009), with the prospect of inter-departmental co-operation between accounting and marketing also seen as a fruitful avenue for capturing customer activity (Roslender and Wilson 2008) and, consequently, competitive advantage. To be sure, voluminous research has documented shifts in the global competitive environment (Stewart 1997), and the rise of alternative managerial structures and information-based organisations (Drucker, 1993) where traditional practices of accounting (Johnson and Kaplan 1987) and management (Stewart 1997) are no longer seen as purposeful, instantiating an apparent need for new measures to be conceived. The area of customer valuation has, as a result, received such attention as the metrics have broadened to incorporate additional variables and data sources (Boyce 2000; Weir 2008; Yani-deSoriano and Slater 2009).

The data previously utilised under earlier forms of CPA stemmed from the internal, and predominantly, financial information held by an organisation about its customers, but the range of data required for the efficacy of CLV and CE is much greater; here the technology of customer valuation has also expanded alongside developments in software and data tracking. Consumer behaviour studies are a key driver in expanding the theoretical underpinnings of customer valuation (Weir 2008), as monitoring purchasing can enable organisations to 
better understand behaviour and thus incorporate it into CLV and CE models (Boyce 2000) monitoring can be conducted through tracking credit card usage (for traditional purchases), or online (for internet shopping).

In addition, post-sales evaluation tools, such as extensive surveys of satisfaction with the level of service rendered, could be used to gather information that is later used for the development of customer action plans (Vaivio 1999). These surveys and the conclusions from active monitoring can then be included in CLV models and later redeployed as part of the broader organisational strategy (Boyce 2000; Cuganesen 2008).

Marketers, through the maturation of internet marketing, have also sought to exploit the capabilities of digital marketing vis-à-vis tracking existing customer behaviour through web browser activity by a wide range of technologies, but notably through cookies-these are small files that are placed on a user's computer that then gathers information about the user's browsing activity or online preferences that is retrieved at a later date, and is subsequently used by, or distributed to, organisations to market other goods or services to the user (Stead and Gilbert 2001). Cookies can also track the volume of online referrals from specific customers therefore act as an additional basis for determining loyalty (see Palmer, 2006), and hence acting as an additional method for value segmentation. Coupled with the concern for meeting customer demands and needs, technology has also afforded an opportunity for firms to engage in mass customisation of marketing services and the provision of goods and services to customer segments (Yani-de-Soriano and Slater 2009) whereby direct-toconsumer forms of online marketing has exploited the data collected on browsing histories and transformed this knowledge into persuasive marketing strategies (Ibid; Boyce 2000).

Going further, Malthouse et al. (2013) suggest that social media can be converged onto aspects of valuing the customer relationship, specifically that integration of social media usage and opinions into valuation models can attempt to measure the probability of retention rates, as well as the potential acquisition of new customers, or the likelihood of termination, which are key variables for advanced forms of CLV and CE metrics (Weir 2008), and thus can lead to more reliable measures of customer value. Even within industries such as banking, online browsing history can have an important impact upon how a customer is classified as potentially a good or bad customer (Persson 2011), suggesting that online presence and behaviour can emerge as an important part of how a customer is perceived, and represented in metrics.

As a result, the organisation itself may use technology to capture data about existing customers, but may also draw from a range of publicly available data - such as government census data (Andon et al. 2001), or buy private data from other sources (Boyce 2000). Indeed, the use of customer databases has become commonplace since the 1980s that marketers have promoted practices of database marketing. Boyce (2002) remarks that this has become an important sub-field within the discipline of marketing and that IT systems and data warehousing have, correspondingly, become part of the contemporary landscape of marketing practice.

Emergent from the increased reliance upon technology is a strongly quantitative understanding of the customer, where shifts in the customer experience can be modelled. This, in turn, leads to a privileging of customer data in shaping the organisation's understanding of the customer, which also influences organisational action by demarcating strategic actions based on which specific segments of customers warrant additional attention.

\section{Irony of Intimacy}

Early attempts at understanding the customer in the 1950s and 1960s followed suggestions that meeting customer needs could lead to increased revenues, and as interested resurfaced in the literature during the 1980s and early 1990s, notions of intimacy also appeared (Treacy and Wiersema 1993) in which knowledge about customers was linked to a perceived intimacy between the customer, as an individual, and the organisation; the implication from this literature being that deeper, or more robust, knowledge about a customer leads to the foster- 
ing of a more intimate relationship, which has the potential for more meaningful interactions with the customer, and, as a result, greater revenues for the organisation.

Customer intimacy, however, becomes ironic in two related ways. Firstly, intimacy is achieved through the reontologisation of the customer as part of a segment, and secondly, intimacy is enabled through studying data collected about customer behaviour and habits.

Throughout the three areas of customer valuation, customers are continually conceptualised as profitable, unprofitable, valuable, loyal, disloyal, assets, desirable, and can become ultimately tradable as commodities. Whilst the notion of the customer as tradable has existed for numerous years in the marketing literature (Levitt 1962), contemporary terminology and usage of 'value' within the metrics presents another dimension to the analysis (cf. Boyce, 2000).

Accounting and valuation imbues an object with visibility (Catasús 2008), which can render certain aspects/objects amenable to calculative technologies and thus create knowledge of the object based on the abstracted accounting numbers. In the context of customer valuation, customers, on both an individual and group level, are subjected to the same objectification, in that customers are reified thorough the calculation process (Bourguignon 2005) and are (re)ontologised as a financial number which is then used as the basis for creating value dualisms with pairings of profitable/unprofitable and desirable/undesirable ultimately stemming from the operation of metrics and CRM. Boyce (2000) remarked on this in practical operation on both the financial services and healthcare industries, noting that the popular business view of customers as assets can also allow for customers to be viewed as liabilities, and therefore to be avoided. As such, in these practical settings, valuation and CRM uses economic considerations to construct dualism, which has the effect of separating all customers on the basis of economic factors and (re)constructing them on the basis of their segmental contributions to revenue.

The process of dualism can also be used to place customers into value hierarchies, where one characteristic or aspect of the dualism is placed above the other, based on the idea that there is a significant difference between dualised pairings, and so that some characteristics emerge as preferable and leads to a hierarchy in which low value customers are subordinated in organisational priority and high value customers are dominant.

Through the creation of hierarchies, CRM evinces a type of management by numbers wherein the accounting metrics allow the customer relationship to become visible in terms of firm value, with preferred customers being those that contribute most to firm value, and therefore attract highly customised marketing communications, and additional resources in the form of tailored goods or services designed to reward them for their perceived loyalty (Boyce 2000).

This can become problematic for at least two reasons. First relating to the creation of value dualisms and hence transforming the customer into segments based on apparent contribution to firm value-also that there is the risk of social exclusion and marginisalistion for the low value customers, accordingly acting as a malevolent force.

To be sure, the professional texts and normative management literature collectively embraces violent metaphors and overtones to impart advice about managing the customer relationship. Publications in the Business Review, for instance, compare low value customers to partners in a bad relationship, and also urge managers to "bite the bullet" (Haenlein and Kaplan 2009, 96) and consider ending such relationships. In addition, publications in Harvard Business Review also proffer advice on terminating costly customer relationships if they damage firm value or if they are not loyal (Reinartz and Kumar 2002; Kumar et al. 2006). Knowing the customer in such instances does not stem from any detailed knowledge of needs as customer management increasingly becomes a form of management-by-numbers (Ogden 1997) in which detailed financial or quantitative knowledge about the customer prevails in determining management strategies and actions.

Secondly, hierarchies (re)frame customer value and worth in terms of firm value, where the emphasis is upon how the customer can contribute towards firm value, and the accompanying CRM schema views the customer as an object to be acquired to drive firm value; 
through this process the customer becomes commodified, and becomes dehumanised through the pursuit of firm value.

\section{The Paradox of Customer Value}

Dehumanisation of the customer takes place through the homogenisation of the customer base that results from using technologies for purposes of segmentation, as customers become part of an aggregated group based on common characteristics or similar behaviour (Boyce 2000).

Here, collected data about preferences, buying behaviour, cross-buying and switching, and so on, that is used to calculate value acts also as a means of differentiation across the customer base. This forms the basis of distinction as individual customers are ignored, and the individual customer is placed in a customer strata or segment. Essentially, personal circumstances become eroded through mass data and customers become aggregated and treated as averages, or as representative of a particular customer segment. Accounting numbers drive this process by making customers visible and leading to abstraction into lifetime values that are representative of idealised relationships and segments.

As a result, the dualisms and hierarchies are then used as the basis of constructing a customer portfolio (Dhar and Glazer 2003; Van Raaij et al. 2003) whereby a company can create a customer base akin to a portfolio in which customers are included on their potential contribution to shareholder value. The emphasis of CE is on increasing firm and shareholder value, despite notions of customer value being at the heart of CE and CLV techniques. There is an inherent tension between customer and shareholder values (Bourguignon 2005), with value being extracted from customers and reassigned to shareholders.

Customer valuations and subsequent customer targeting and retention and marketing strategies are already seen to be having effects in business areas as diverse as health insurance provision (Boyce 2000; Andon et al. 2001), gas and electricity provision, and telecommunications and Internet service provision (Boyce 2002). The effects of customer valuations have also been seen in a range of basic financial services such as credit provision and bill payment services (Carbo et al. 2007). The common finding amongst each of these sectors is that customer profitability calculations and valuations are leading to a split in the customer base where richer customers are privileged with better access and exclusive offers. This is evident from the literature on banking, where Boyce (2000) has noted that resources are reallocated to more valuable customers.

Within the literature, it has been found that banks regularly conduct customer profitability calculations and retain more profitability customers, whilst trying to transform unprofitable customers (Andon et al. 2001). Accordingly banks are refusing to deal with poor or disadvantaged customers; however, in today's environment, banking is a service that most people, regardless of social or economic background, depend upon, thus the refusal by some banks to transact with poorer customers could lead to their alienation from the banking industry (Carbo et al. 2007; Weir 2008). However it is likely that banks will not risk negative publicity by firing customers, so they might be more inclined to discipline unwanted customers by imposing high charges and fees (Boyce 2000). In addition, target marketing, which results from the identification of profitable customers, could see richer customers being offered exclusive services and products, whilst poorer customers are likely to be offered substandard services (Ibid.). This would only serve to further the alienation of particular customers or customer groups.

As well as functioning as a means for value extraction for shareholders, the hierarchies encouraged by CRM can also be linked to logics of domination (cf. Warren, 1998), particularly as the customer value hierarchies devalue particular groups according to their perceived profitability or loyalty, which allows the devalued customers to be dominated, and thus marginalised or alienated by the organisation (Boyce 2000). Furthermore, Carbo et al. (2007) point out that financial exclusion is often the case for low-income customers in the financial service industry, and since the devalued customers tend to be economically disadvantaged 
customers (Boyce 2000), widespread use of CRM in this sense may lead to further marginalisation of poor customers whilst richer customers may prosper (cf. Weir 2008).

\section{Malevolence of Customer Management}

Indeed, such objections to customer valuation stressed in both accounting and marketing literature suggests that through CLV and CRM, customers can be alienated and marginalised (Boyce 2000). But going further scholars have also noted that use of CRM and related valuation models places all customers under the managerialist gaze of valuation (Roslender and Hart 2010; Boyce 2000; Bourguignon 2005), with practice in the area more focused on implementing exotic metrics based on hard accounting numbers (Roslender and Hart 2010) and closer links to financial theories and models (Weir 2008), that leads to not only a dehumanisation of all customers, but also a silencing of customer voices (cf. Roslender and Hart 2010) in favour of the abstracted measures of value that guide management action.

The commonality across these studies suggests that accounting in the form of customer valuation becomes not only an important management tool, in terms of determining strategic priorities, but also a key mode of control. The largely quantitative metrics broadly comprise the organisation's knowledge of customers, and unique or individual elements of each customer are ignored and replaced by heterogeneous elements resulting from the calculations (cf. Cuganesen 2008), leading to the implementation of a formal management of customers based on accounting measure (Ogden 1997), where customers' needs are ignored (Roslender and Hart 2010) and essentially replaced with what the organisation wishes to sell them.

As the technologies underlying data collection and valuation becomes increasingly sophisticated, it is likely that homogenisation of the customer base will become more prevalent, leading to, as feared by some (Boyce 2000; Carbo et al. 2007) that customers will be treated according to their respective socio-economic circumstances and be segmented according to emergent data stereotypes. For instance, customers become divided according to lifestyle stereotypes (Andon et al. 2001), which can also lead to a blanket treatment of particular areas or neighbourhoods of cities (Boyce 2000) leading to a redefinition of the customer that is facilitated according to their potential capacity for contributing to firm or shareholder value; a shift which is in line with the hegemonic interests of capital (cf. Bourguignon 2005), and therefore leads to forms of social stratification.

Additionally, there are ethical concerns over the use of data collection methods (Boyce 2000; 2002; Palmer 2006) which can infringe upon a customer's privacy when using the internet, particularly involving the distribution of third party cookies and the storage of data collected from them (see Palmer 2006).

Usage becomes further problematic in business applications as metrics determining value can include variables within the calculative technologies such as age, class, race and gender, which are already seen as important variables in applications of CLV and CRM in both the airline industry (Liou and Tzeng 2010) and commercial banking (Haenlein et al. 2007) as these can drive (or decrease) firm value and therefore act as important segmentation variables. Religious affiliation can also become a determinant in CLV calculations, and additionally a factor of customer value. The issue here is that application of the metrics can lead to particular customers or customer groups being portrayed as undesirable, unprofitable and disloyal, but through the inclusion of social and cultural, and even racial it becomes possible for services to be denied to customer groups on the basis of gender, race or religion. Since accounting is often seen in practical contexts as creating neutral and objective information (see Mouck 2004), the 'facts' of customer value can therefore become prefigurative as the variables used can support pre-existing managerial biases surrounding the desirability of customers.

For Boyce $(2000 ; 2002)$ the process of segmentation reinforces already existing social stratification, and including data on issues as diverse as religious affiliation, race or gender, places these within calculative regimes and can lead to social stratification along these lines, and customers belonging to a particular religion, race or gender, can become excluded, al- 
ienated or marginalised from particular organisations or industries, such as in healthcare (Boyce 2000) or banking (Andon et al. 2001; Carbo et al. 2007; Persson, 2011).

As a result, the claimed relationship management facet of CRM becomes malevolent on the basis that society is recast as a cluster of marketing segments that exhibit either desirable or undesirable characteristics, and consequently, CRM can be seen as a way of justifying the denial of service provision to "undesirable" customers-such as poor customers being denied access to healthcare (Boyce 2000).

Additionally, the interface between technology and valuation and the emphasis upon CRM may also engender a shift in the buyer-seller relationship to such an extent that there may be "too much emphasis" on customers (Yani-de-Soriano and Slater 2009: 461) and may stimulate broader social harm by over-emphasising the importance, or centrality, of consumption (Ibid.).

In conclusion, the link between technology and valuation of the customer that underpins CRM therefore acts as a calculative regime in which all customers become represented, and hence understood, as numbers, creating an objective knowledge about customers that invites managerial intervention based upon anticipated movements in the overall level of firm, or shareholder, value. This process subsequently commodifies the customer. Intervention, at the level of CRM, commonly leads to poor and disadvantaged groups or customers being disciplined and denied organisational access on the basis of their negative contribution to organisational value, leading to marginalisation of customers.

\section{References}

Andon, Paul, Jane Baxter, and Graham Bradley. 2001. Calculating the economic value of customers to an organisation. Australian Accounting Review 11 (1): 62-72.

Bayon, Tomas, Jens Gutsche, and Hans Bauer. 2002. Customer Equity Marketing: Touching the Intangible. European Management Journal 20 (3): 213-222.

Bellis-Jones, Robin. 1989. Customer Profitability Analysis. Management Accounting 67 (2): 26-28

Berger, Paul D., Ruth N. Bolton, Douglas Bowman, Elten Briggs, V. Kumar, A. Parasuraman and Creed Terry. 2002. Marketing Actions and the Value of Customer Assets: A Framework for Customer Asset Management. Journal of Service Research 5: 9-54.

Blattberg, Robert C. and John Deighton. 1996. Manage Marketing by the Customer Equity Test. Harvard Business Review 74 (4): 136-144.

Bourguignon, Annick. 2005. Management accounting and value creation: the profit and loss of reification. Critical Perspectives on Accounting 16: 353-389.

Boyce, Gordon. 2000. Valuing Customers and Loyalty: The Rhetoric of Customer Focus Versus the Reality of Alienation and Exclusion of (de valued) Customers. Critical Perspectives on Accounting 11 (6): 649-689.

Boyce, Gordon. 2002. Beyond Privacy: The Ethics of Customer Information Systems, paper presented at Informing Science, June 2002, available at: http://www.proceedings.informingscience.org/IS2002Proceedings/papers/Boyce230Beyon.pdf.

Bromwich, Michael. 1990. The Case for Strategic Management Accounting: The Role of Accounting Information for Strategy in Competitive Markets. Accounting, Organizations and Society 15: 27-46

Carbo, Santiago, Edward Gardener and Philip Molyneux. 2007. Financial Exclusion in Europe. Public Money \& Management 27 (1): 21-27.

Catasús, Bino. 2008. In Search of Accounting Absence. Critical Perspectives on Accounting 19 (7): 1004-1019.

Cuganesan, Suresh. 2008. Calculating Customer Intimacy: Accounting Numbers In A Sales And Marketing Department. Accounting, Auditing \& Accountability Journal 21 (1): 78-103.

Dhar, Ravi, and Rashi Glazer. 2003. Hedging Customers. Harvard Business Review 81 (5): 3-8.

Drucker, Peter. 1954. The Practice of Management. Harper: New York, NY.

Drucker, Peter. 1993. Post-Capitalist Society. HarperCollins: New York, NY.

Foster, George and Mehendra Gupta. 1994. Marketing, cost management and management Accounting. Journal of Management Accounting Research 6: 43-77

Guilding, Chris, and Lisa McManus. 2002. The Incidence, Perceived Merit and Antecedents of Customer Accounting: An Exploratory Note. Accounting, Organizations and Society, 27 (1): 45-59. 
Haenlein, Michael and Andreas Kaplan. 2009. Unprofitable customers and their management. Business Horizons 52 (1): 89-9

Haenlein, Michael, Andreas Kaplan, and Anemone Beeser. 2007. A Model to Determine Customer Lifetime Value in a Retail Banking Context. European Management Journal 25 (3): 221-234.

Johnson, Thomas H. and Robert S. Kaplan. 1987. Relevance Lost: the Rise and Fall of Management Accounting. Boston: Harvard Business School Press.

Kumar, V., Rajkumar Venkatesan, and Werner Reinartz. 2006. Knowing What To Sell, When, And To Whom. Harvard Business Review, March: 131-137

Levitt, Theodore. 1962. Innovation in Marketing: New Perspectives for Profit and Growth. London: Pan.

Liou, James J.H., and Gwo-Hshiung Tzeng. 2010. A Dominance-Based Rough Set Approach to Customer Behavior in the Airline Market. Information Sciences 180: 2230-2238

Malthouse, Edward C., Michael Haenlein, Bernd Skiera, Egbert Wege and Michael Zhang. 2013. Managing Customer Relationships in the Social Media Era: Introducing the Social CRM House. Journal of Interactive Marketing 27 (4): 270-80

Miles, Raymond E. and Charles C. Snow. 1978. Organizational strategy, structure, and process. New York: McGraw-Hill.

Mouck, Tom. 2004. Institutional Reality, Financial Reporting and the Rules of the Game. Accounting, Organizations and Society 29: 525-541.

Mulhern, Francis J. 1999. Customer Profitability Analysis: Measurement, Concentration, and Research Directions. Journal of Interactive Marketing 13 (1), 25-40.

Ogden, S.G. 1997. Accounting for Organisational Performance: The Construction of the Customer in

the Privatised Water Industry. Accounting, Organizations and Society 22 (6): 529-556

Palmer, Daniel E. 2006. Pop-Ups, Cookies, and Spam: Toward a Deeper Analysis of the Ethical Significance of Internet Marketing Practices. Journal of Business Ethics 58 (1-3): 271-280

Persson, Andreas. 2011. The management of customer relationships as assets in the retail banking sector. Journal of Strategic Marketing 19 (1): 105-119

Porter Michael. 1985. Competitive Advantage. Free Press, New York.

Reinartz, Werner and V. Kumar. 2002. The mismanagement of customer loyalty. Harvard Business Review, July, 86-97

Roslender, Robin. 1995. Accounting For Strategic Positioning: Responding To The Crisis In Management Accounting. British Journal of Management 6 (1): 45-57.

Roslender, Robin and Susan Hart. 2010. Taking the customer into account: transcending the construction of the customer through the promotion of self-accounting. Critical Perspectives on Accounting 7 (21): 739-753

Roslender, Robin and Richard Wilson. 2008. The Marketing/Accounting Synergy: A Final Word But Certainly Not The Last Word. Journal of Marketing Management, 24 (7/8): 865-76.

Rust, Roland T, Katherine Lemon, and Valarie A. Zeithaml. 2004. Return on Marketing: Using Customer Equity to Focus Marketing Strategy. Journal of Marketing 68 (1): 109-127

Simmonds, Kenneth. 1982. Strategic management accounting for pricing: a case example. Accounting and Business Research 12: 206-214.

Stead, Bette Ann and Jackie Gilbert. 2001. Ethical Issues in Electronic Commerce. Journal of Business Ethics 34 (2): 75-85.

Stewart, Thomas. 1997. Intellectual Capital. London: Nicolas Brearly Publishing.

Treacy, Michael, and Fred Wiersema. 1993. Customer intimacy and other value disciplines, Harvard Business Review 71 (1): 84-93.

Van Raaij, Erik. M., Maarten J.A. Vernooij and Sander van Triest. 2003. The Implementation of customer profitability analysis: A case study. Industrial Marketing Management 32: 573-583.

Vaivio, Juhani. 1999. Examining 'The Quantified Customer'. Accounting, Organizations and Society, 24 (8): 689-715.

Verhoef, Peter C. 2003. Understanding the effect of customer relationship management efforts on customer retention and customer share development. Journal of Marketing 67 (1): 30-45.

Warren, Karen. 1998. The Power and Promise of Ecological Feminism. In Environmental Philosophy, edited by M. Zimmerman, J. Callicott, G. Sessions, K. Warren and J. Clark, 325-344. Upper Saddle River, NJ: Prentice-Hall.

Webster, Frederick. 1988. The Rediscovery Of The Marketing Concept. Business Horizons 31 (3): 2939. 
Weir, Kenneth. 2008. Examining the theoretical influences of customer valuation metrics. Journal of Marketing Management 24(7/8): 797-824.

Yani-de-Soriano, Mirella and Stephanie Slater. 2009. Revisiting Drucker's theory. Journal of Management History 15 (4): 452-466.

\section{About the Author}

\section{Kenneth Weir}

is a lecturer in accounting at the University of Leicester, and is a member of its Centre for Philosophy and Political Economy. His current research focuses on two areas: the emergence of accounting techniques, and the nature of academic publishing. 